\title{
Comparison of early hemodynamic performance of 3 aortic valve bioprostheses
}

\author{
Murat Ugur, MD, Rakesh M. Suri, MD, DPhil, Richard C. Daly, MD, Joseph A. Dearani, MD, \\ Soon J. Park, MD, Lyle D. Joyce, MD, PhD, Harold M. Burkhart, MD, Kevin L. Greason, MD, and \\ Hartzell V. Schaff, MD
}

\begin{abstract}
Objective: The study objective was to determine whether the new-generation Trifecta (St Jude Medical Inc, St Paul, Minn) bovine aortic valve bioprosthesis, which is designed for supra-annular positioning, produces early postoperative hemodynamic results comparable to or better than those of the Mitroflow (Sorin Group, Milan, Italy) or Perimount Magna (Edwards Lifesciences Corp, Irvine, Calif) bovine aortic valve bioprostheses.
\end{abstract}

\begin{abstract}
Methods: We retrospectively reviewed the medical records of patients who underwent aortic valve replacement with a Trifecta, Mitroflow, or Perimount Magna bovine pericardial prosthesis at Mayo Clinic between June 2007 and December 2012 and analyzed early postoperative hemodynamic performance by Doppler echocardiography.

Results: A total of 1436 patients underwent aortic valve replacement (Trifecta in 196, Mitroflow in 1135, Perimount Magna in 105). Preoperative characteristics and early clinical outcomes were similar among the 3 valve groups. The average mean gradients were lower and valve areas were greater with the Trifecta valves. For the Trifecta, Mitroflow, and Perimount Magna valves, the average mean gradient was $11.4 \mathrm{~mm} \mathrm{Hg}, 16.9 \mathrm{~mm} \mathrm{Hg}$, and $14.1 \mathrm{~mm} \mathrm{Hg}$, respectively; the effective orifice area was $2.22 \mathrm{~cm}^{2}, 1.85 \mathrm{~cm}^{2}$, and $2.09 \mathrm{~cm}^{2}$, respectively; and the indexed effective orifice area was $1.14 \mathrm{~cm}^{2} / \mathrm{m}^{2}, 0.96 \mathrm{~cm}^{2} / \mathrm{m}^{2}$, and $1.07 \mathrm{~cm}^{2} / \mathrm{m}^{2}$, respectively (all $P<.001$ ). Similar statistical significance was found when data were stratified by valve size. Severe prosthesis-patient mismatch (indexed effective orifice area $<0.60 \mathrm{~cm}^{2} / \mathrm{m}^{2}$ ) was detected in $1.3 \%$ of patients $(\mathrm{n}=2 / 150)$ with the Trifecta, $5.8 \%$ of patients $(n=44 / 758)$ with the Mitroflow, and $3.2 \%$ of patients $(n=3 / 95)$ with the Perimount Magna $(P=.048)$.
\end{abstract}

Conclusions: Early hemodynamic postoperative performance of the Trifecta bioprosthesis is favorable. Additional follow-up should determine whether these small hemodynamic differences will persist and influence later clinical outcomes. (J Thorac Cardiovasc Surg 2014;148:1940-6)

Bioprosthetic valves are recommended for patients aged more than 65 years who require valve replacement and for patients who have medical contraindications to systemic anticoagulation or who prefer to avoid warfarin because of lifestyle considerations. ${ }^{1}$ Stented bovine pericardial prostheses are considered to have better hemodynamic results (lower gradients) than stented porcine valves. ${ }^{2-4}$ The Mitroflow (Sorin Group, Milan, Italy) bovine bioprosthesis and the Perimount Magna (Edwards Lifesciences Corp, Irvine, Calif) bovine bioprosthesis have been used in clinical practice with favorable outcomes since 1982 and 2003, respectively. ${ }^{4-7}$

From the Division of Cardiovascular Surgery, Mayo Clinic, Rochester, Minn.

Disclosures: Dr Schaff was an investigator in the Food and Drug Administrationmandated clinical trial of the Trifecta prosthesis, a study that was supported by St Jude Medical Inc. Dr Suri reports consulting fees from Sorinand and grant support from Sorin, Edwards, and St Jude. All other authors have nothing to disclose with regard to commercial support.

Read as a poster at the 7th Biennial Congress of the Society for Heart Valve Disease and Heart Valve Society of America, Venice, Italy, June 22-25, 2013.

The Mayo Clinic does not endorse the products mentioned in this article.

Received for publication Sept 13, 2013; revisions received Dec 6, 2013; accepted for publication Dec 20, 2013; available ahead of print Feb 13, 2014.

Address for reprints: Hartzell V. Schaff, MD, Division of Cardiovascular Surgery, Mayo Clinic, 200 First St SW, Rochester, MN 55905 (E-mail: schaff@mayo.edu). $0022-5223 / \$ 36.00$

Copyright (c) 2014 by The American Association for Thoracic Surgery

http://dx.doi.org/10.1016/j.jtcvs.2013.12.051
The Trifecta aortic valve (St Jude Medical Inc, St Paul, Minn) is a new bovine bioprosthesis approved in 2011 that incorporates ethanol-based anticalcification technology. Recent reports have documented satisfactory earlyterm (predischarge to 1-2 years) clinical and hemodynamic performance after aortic valve replacement (AVR) using the Trifecta valve. ${ }^{8,9}$ Dell'Aquila and colleagues ${ }^{10}$ compared AVR outcomes for the Trifecta with previously published data and found lower mean gradients at hospital discharge. Wendt and colleagues ${ }^{11}$ reported that their comparison of the 6-month hemodynamics of the Trifecta valve and the Perimount Magna and Magna Ease valves (Edwards Lifesciences Corp) indicated that mean pressure gradients and aortic valve areas seemed better with the Trifecta, but multivariate covariance analysis showed no influence of prosthesis type on either variable. In this study, we compared the early hemodynamic outcomes of the new generation Trifecta valve bioprosthesis with those of the widely used Mitroflow and Perimount Magna aortic valve bioprostheses.

\section{MATERIALS AND METHODS}

In this retrospective study, after obtaining approval from the Mayo Clinic Institutional Review Board, we searched the institutional cardiovascular surgery database to identify all patients who had undergone AVR between January 2007 and December 2012. We included all patients 

Abbreviations and Acronyms
AVR $=$ aortic valve replacement
$\mathrm{EOA}=$ effective orifice area
$\mathrm{EOAI}=$ effective orifice area index
LVOT $=$ left ventricular outflow tract
PPM = prosthesis-patient mismatch

who had previously given written permission for use of their medical records for research purposes and who had undergone AVR with the Trifecta, Mitroflow, or Perimount Magna bovine pericardial valve bioprosthesis. Demographic and clinical information, including early mortality and echocardiographic reports, were abstracted from medical records and the Mayo Clinic Cardiovascular Surgery Clinical Database. We compared preoperative clinical characteristics, operative data, and early postoperative hemodynamic outcomes of patients.

Operations were performed using standard cardiopulmonary bypass and cold-blood cardioplegic cardiac arrest. After aortotomy and excision of the diseased aortic valve, the decisions regarding surgical technique and valve type were made by the operating surgeon. Choice of valve was made by the surgeon, and this selection was not based on clinical or anatomic considerations. AVR was performed with interrupted noneverting pledget-reinforced sutures after measurement of the aortic annulus with valve-sizers supplied by manufacturers. The aortotomy was closed using primary suture or patch closure, as necessary.

The Trifecta valve is a completely supra-annular-positioned pericardial aortic valve constructed from a single bovine pericardial sheet externally mounted on a titanium stent and a sewing ring. ${ }^{8,10}$ It has been in clinical use in the United States since 2007. The Mitroflow valve is a glutaraldehyde-fixed bovine pericardial bioprosthesis constructed with bovine pericardium mounted on the outside of a flexible polyestercovered acetyl homopolymer stent and sutured into place. ${ }^{12,13}$ The valve has been used in Europe since 1987 and in the United States since 2007. The Perimount Magna valve is a modification of the Perimount valve, and it has been used since 2002. It is mounted on an Elgiloy (Elgin, Ill) frame, and, in addition to glutaraldehyde fixation, the bovine pericardial cusps are treated with surfactant and thermal exposure to retard calcification.

All patients underwent 2-dimensional and Doppler transthoracic echocardiographic examinations preoperatively and before discharge from the hospital. Standard prosthetic valve measurements were evaluated, including mean gradient, effective orifice area (EOA), and effective orifice area index (EOAI). The mean aortic valve gradient was measured using continuous-wave Doppler velocity spectra from the transducer position that yielded maximum velocity across the valve or prosthesis and was calculated by the modified Bernoulli equation. EOA was calculated automatically from the continuity equation by using the left ventricular outflow tract (LVOT) area and the time velocity integral. The EOAI was obtained by dividing the EOA by the body surface area. Prosthesis-patient mismatch (PPM) was evaluated as severe if the EOAI was $0.60 \mathrm{~cm}^{2} / \mathrm{m}^{2}$ or less. ${ }^{14}$

\section{Statistical Methods}

Descriptive statistics are reported as number (percentage) for categoric variables and as mean (standard deviation) or median (range) for continuous variables, as appropriate. The categoric variables of the patients with Trifecta, Mitroflow, or Perimount Magna bioprostheses were compared using the chi-square test, and the continuous variables were compared using the analysis of variance or the Kruskal-Wallis test, as appropriate. All statistical tests were 2-sided.

\section{RESULTS}

A total of 3896 patients underwent AVR at Mayo Clinic, Rochester, Minnesota, from June 2007 to December 2012. A total of 990 patients received mechanical prostheses, 2876 patients received bioprostheses, and 30 patients received homografts. We evaluated 1436 patients who underwent AVR with the Trifecta (196 [14\%]), Mitroflow (1135 [79\%]), or Perimount Magna (105 [7\%]) bioprosthesis. Of these 1436 patients, most (1315 [91.6\%]) had severe aortic valve stenosis and one fourth $(373$ [26.0\%]) had moderate or severe aortic valve regurgitation. The baseline characteristics of the 1436 patients and their preoperative echocardiographic findings are detailed in Table 1. The mean LVOT diameter, as measured on preoperative transthoracic echocardiograms, was $2.3 \pm 0.3 \mathrm{~cm}, 2.26 \pm 0.20$ $\mathrm{cm}$, and $2.27 \pm 0.20 \mathrm{~cm}$ in the Trifecta, Mitroflow, and Perimount Magna valves, respectively $(P=.22)$, and was statistically indistinguishable among implant groups.

Concomitant coronary artery bypass grafting and other valve surgeries were performed more frequently in patients with the Mitroflow $(P<.001)$, but there was no difference in use of annular enlargement among the 3 groups $(P=.73)$. Concomitant surgical procedures are shown in Table 2. In the Mitroflow group, crossclamp and perfusion times were slightly longer than those in the Trifecta and Perimount Magna groups (for isolated AVR, $62 \pm 27$ minutes, $53 \pm 30$ minutes, and $55 \pm 26$ minutes, respectively; $P<.001)$. Thirty-day mortality and neurologic event rates were similar among groups; for the Trifecta, Mitroflow, and Perimount Magna groups, there were 3 early deaths $(1.5 \%), 34$ early deaths $(3.0 \%)$, and 1 early death $(1 \%)$ $(P=.27)$, respectively, and 3 strokes $(1.5 \%), 17$ strokes $(1.5 \%)$, and no strokes $(P=.45)$, respectively (Table 3$)$.

For the Trifecta, Mitroflow, and Perimount Magna groups, the mean transprosthetic gradient on predischarge postoperative echocardiograms at a mean of $4.7 \pm 2.6$ days after operation was $11.4 \mathrm{~mm} \mathrm{Hg}, 16.9 \mathrm{~mm} \mathrm{Hg}$, and $14.1 \mathrm{~mm} \mathrm{Hg}$, respectively $(P<.001)$; prosthetic valve EOA was $2.22 \mathrm{~cm}^{2}, 1.85 \mathrm{~cm}^{2}$, and $2.09 \mathrm{~cm}^{2}$, respectively $(P<.001)$; and EOAI was $1.14 \mathrm{~cm}^{2} / \mathrm{m}^{2}, 0.96 \mathrm{~cm}^{2} / \mathrm{m}^{2}$, and $1.07 \mathrm{~cm}^{2} / \mathrm{m}^{2}$, respectively $(P<.001)$ (Table 4$)$. Similar statistical significance was found when data were stratified by labeled valve size (Figure 1).

The rate of severe PPM after implantation of the Trifecta, Mitroflow, and Perimount Magna valves was 1.3\% (2/150), $5.8 \%(44 / 758)$, and $3.2 \%(3 / 95)$, respectively, for all patients $(P=.048)$, and $2.1 \%(2 / 97), 7.2 \%(25 / 347)$, and $3.4 \%(2 / 59)(P=.11)$, respectively, for patients undergoing isolated AVR.

\section{DISCUSSION}

To our knowledge, this is the first study to compare early postoperative outcomes for the more recently approved 
TABLE 1. Characteristics of 1436 patients who underwent aortic valve replacement with 1 of 3 bovine bioprostheses*

\begin{tabular}{|c|c|c|c|c|}
\hline \multirow[b]{2}{*}{ Variable } & \multicolumn{3}{|c|}{ Bioprosthesis $(N=1436)$} & \multirow[b]{2}{*}{$P$ valu } \\
\hline & $\begin{array}{c}\text { Trifecta (St Jude Medical, } \\
\text { St Paul, Minn) }(n=196)\end{array}$ & $\begin{array}{l}\text { Mitroflow (Sorin Group, } \\
\text { Milan, Italy) }(\mathbf{n}=\mathbf{1 1 3 5})\end{array}$ & $\begin{array}{c}\text { Perimount Magna } \\
\text { (Edwards Lifesciences Corp, } \\
\text { Irvine, Calif) }(\mathbf{n}=\mathbf{1 0 5})\end{array}$ & \\
\hline Age, y & $74.5 \pm 8.5$ & $75 \pm 9.6$ & $75.4 \pm 7.6$ & .55 \\
\hline Male sex & $129(65.8)$ & $695(61.2)$ & $66(62.9)$ & .47 \\
\hline BMI, $\mathrm{kg} / \mathrm{m}^{2}$ & $29.3 \pm 5.5$ & $29.7 \pm 6.2$ & $29.6 \pm 6.2$ & .90 \\
\hline BSA & $1.97 \pm 0.2$ & $1.95 \pm 0.2$ & $1.96 \pm 0.3$ & .54 \\
\hline Smoking & $49 / 88(55.7)$ & $455 / 820(55.5)$ & $50 / 95(52.6)$ & .87 \\
\hline \multicolumn{5}{|l|}{ Medical history } \\
\hline Hypertension & $152 / 195(77.9)$ & $890(78.4)$ & $74(70.5)$ & .16 \\
\hline Diabetes mellitus & $45(23.1)$ & $311(27.4)$ & $28(26.7)$ & .45 \\
\hline Dialysis-dependent RF & $1(0.5)$ & $18(1.6)$ & $1(1)$ & .46 \\
\hline Myocardial infarction & $26(13.3)$ & $190(16.7)$ & $13(12.4)$ & .28 \\
\hline Cardiac surgery & $27(13.8)$ & $219(19.3)$ & $13(12.4)$ & .05 \\
\hline Previous CABG & $17(8.7)$ & $158(13.9)$ & $11(10.5)$ & .10 \\
\hline Atrial fibrillation & $19(9.7)$ & $143(12.6)$ & $6(5.7)$ & .07 \\
\hline \multicolumn{5}{|l|}{ Risk factors } \\
\hline CVA & $11 / 47(23.4)$ & $69 / 240(28.8)$ & $4 / 19(21.1)$ & .61 \\
\hline PVD & $14 / 195(7.2)$ & $152(13.4)$ & $8(7.6)$ & .02 \\
\hline COPD & 22/195 (11.3) & $239(21.1)$ & $23(21.9)$ & .006 \\
\hline Aortic stenosis & $175(89.3)$ & $1037(91.4)$ & $103(98.1)$ & .03 \\
\hline Aortic regurgitation & $57(34.1)$ & $302(30.9)$ & $14(16.5)$ & .01 \\
\hline \multicolumn{5}{|c|}{ Preoperative echocardiographic results } \\
\hline Ejection fraction, $\%$ & $60.81 \pm 10.7$ & $59.07 \pm 13.5$ & $60.09 \pm 11.3$ & .87 \\
\hline LVOT diameter, $\mathrm{cm}$ & $2.3 \pm 0.3$ & $2.26 \pm 0.2$ & $2.27 \pm 0.2$ & .22 \\
\hline Mean gradient, $\mathrm{mm} \mathrm{Hg}$ & $47.91 \pm 17.5$ & $47.08 \pm 16.9$ & $50.65 \pm 14.4$ & .08 \\
\hline $\mathrm{EOA}, \mathrm{cm}^{2}$ & $1.11 \pm 0.8$ & $1.04 \pm 0.7$ & $0.92 \pm 0.4$ & .50 \\
\hline EOAI, $\mathrm{cm}^{2} / \mathrm{m}^{2}$ & $0.48 \pm 0.2$ & $0.47 \pm 0.2$ & $0.47 \pm 0.2$ & .83 \\
\hline
\end{tabular}

$A V$, Aortic valve; $B M I$, body mass index; $B S A$, body surface area; $C A B G$, coronary artery bypass grafting; $C O P D$, chronic obstructive pulmonary disease; $C V A$, cerebrovascular accident; $E O A$, effective orifice area; $E O A I$, effective orifice area index; $L V O T$, left ventricular outflow tract; $P V D$, peripheral vascular disease; $R F$, renal failure. *Values are number (percentage) or mean \pm standard deviation unless indicated otherwise.

Trifecta aortic valve with those of the Mitroflow and Perimount Magna aortic valves, which have been in use longer. Mean gradients were slightly lower, and EOA and EOAI were greater in the Trifecta group than in the Perimount Magna and Mitroflow groups, as assessed by early postoperative hemodynamic data before hospital discharge. Similar results were obtained when data were stratified by commercially labeled valve size.
Each of the 3 valves studied was designed for supraannular positioning, which facilitates implantation in small annuli and reduces or eliminates the need for other surgical alternatives, such as stentless heterografts or homografts and root enlargement procedures to avoid PPM. ${ }^{1,15,16}$ Stentless devices have been associated with a $20 \%$ rate of failure at 10-year follow-up, ${ }^{1,10,17}$ and reoperation may require aortic root replacement, with increased mortality

TABLE 2. Concomitant surgical procedures in 1436 patients who underwent aortic valve replacement with 1 of 3 bovine bioprostheses*

\begin{tabular}{|c|c|c|c|c|}
\hline \multirow[b]{2}{*}{ Procedure } & \multicolumn{3}{|c|}{ Bioprosthesis $(\mathrm{N}=1436)$} & \multirow[b]{2}{*}{$P$ value } \\
\hline & Trifecta $(n=196)$ & Mitroflow $(n=1135)$ & Perimount Magna $(\mathbf{n}=105)$ & \\
\hline Aortic annular enlargement & $5(2.6)$ & $44(3.9)$ & $4(3.8)$ & .73 \\
\hline Ascending aorta graft replacement & $5(2.6)$ & $43(3.8)$ & $0(0.0)$ & .07 \\
\hline Myectomy & $11(5.6)$ & $88(7.8)$ & $0(0.0)$ & .001 \\
\hline Concomitant CABG & $56(28.6)$ & $499(44.0)$ & $38(36.2)$ & $<.001$ \\
\hline Mitral valve repair & $3(1.5)$ & $37(3.3)$ & $2(1.9)$ & .43 \\
\hline Mitral valve replacement & $0(0.0)$ & $71(6.3)$ & $0(0.0)$ & $<.001$ \\
\hline Tricuspid valve repair & $6(3.1)$ & $79(7.0)$ & $1(1)$ & .005 \\
\hline Tricuspid valve replacement & $4(2.0)$ & $19(1.7)$ & $0(0.0)$ & .39 \\
\hline Atrial septal defect & $2(1.0)$ & $62(5.5)$ & $0(0.0)$ & $<.001$ \\
\hline
\end{tabular}

$C A B G$, Coronary artery bypass grafting. *Values are number (percentage). 
TABLE 3. Comparison of operative findings in 1436 patients who underwent aortic valve replacement with 1 of 3 bovine bioprostheses*

\begin{tabular}{|c|c|c|c|c|}
\hline \multirow[b]{2}{*}{ Variable } & \multicolumn{3}{|c|}{ Bioprosthesis $(N=1436)$} & \multirow[b]{2}{*}{$P$ value } \\
\hline & Trifecta $(n=196)$ & Mitroflow $(n=1135)$ & Perimount Magna $(n=105)$ & \\
\hline Isolated AVR & $129(65.8)$ & $521(45.9)$ & 65 (61.9) & $<.001$ \\
\hline Concomitant valve surgery & $13(6.6)$ & $173(15.2)$ & $2(1.9)$ & $<.001$ \\
\hline $\mathrm{CPB}$ time, $\min$ & $83 \pm 52$ & $110 \pm 57$ & $86 \pm 48$ & $<.001$ \\
\hline CPB time for isolated AVR, min & $67 \pm 40$ & $83 \pm 43$ & $71 \pm 38$ & $<.001$ \\
\hline XCL time, $\min$ & $66 \pm 41$ & $82 \pm 40$ & $68 \pm 34$ & $<.001$ \\
\hline XCL time for isolated AVR, min & $53 \pm 30$ & $62 \pm 27$ & $55 \pm 26$ & $<.001$ \\
\hline Reoperation for bleeding & $4(2.0)$ & $51(4.5)$ & $6(5.7)$ & .22 \\
\hline Reoperation for bleeding for isolated AVR & $4 / 196(3.1)$ & $13 / 521(2.5)$ & $3 / 65(4.6)$ & 60 \\
\hline Low CO & $1(0.5)$ & $27(2.4)$ & $0(0)$ & .07 \\
\hline Mortality, $\leq 30 \mathrm{~d}$ & $3(1.5)$ & $34(3.0)$ & $1(1)$ & .27 \\
\hline Mortality, $\leq 30 \mathrm{~d}$, for isolated AVR & 2/129 (1.6) & $6 / 521(1.2)$ & $0 / 65(0)$ & .62 \\
\hline Stroke & $3(1.5)$ & $17(1.5)$ & $0(0)$ & .45 \\
\hline Stroke for isolated AVR & $1 / 129(0.8)$ & $4 / 521(0.8)$ & $0 / 65(0)$ & .78 \\
\hline TIA & $1 / 171(0.6)$ & $9 / 1112(0.8)$ & $0(0)$ & .63 \\
\hline TIA for isolated AVR & $1 / 113(0.9)$ & $3 / 511(0.6)$ & $0(0)$ & .76 \\
\hline
\end{tabular}
mean \pm standard deviation unless indicated otherwise.

risk. ${ }^{10}$ Homografts also have a high reoperation risk and an age-related risk of structural valve deterioration. ${ }^{18}$ Supraannular positioning of bioprostheses is thought to improve hemodynamic outcomes by minimizing stent and sewing ring interference with left ventricular ejection., ${ }^{9,15}$

These 3 pericardial valves are all being used in current clinical practice. The Mitroflow valve has satisfactory EOA and hemodynamic performance, and studies show that its rate of failure requiring replacement is $3.7 \%$ to $4.1 \%$ at 20 years and that the rate of freedom from valverelated death is $82.9 \%$ to $89.1 \%{ }^{6,7}$ In US studies, the 3 -year actuarial freedom from valve-related death, reoperation, and structural dysfunction has been reported as $97.0 \%$, $97.9 \%$, and $99.2 \%$, respectively. ${ }^{13}$ In this early follow-up, primary reasons for explantation were structural valve deterioration and endocarditis; 3-year valve-related events were similar to those for other bioprosthetic valves. ${ }^{13}$

The Perimount Magna valve has been shown to have lower postoperative gradients and greater EOA and EOAI than the earlier-generation Perimount valve. ${ }^{19}$ In early hemodynamic studies, this prosthesis may have slightly lower gradients and similar valve areas than the Mitroflow and the Epic (St Jude Medical) prostheses. ${ }^{20}$

The Trifecta valve is a relatively new prosthesis with few data available yet on clinical and hemodynamic outcomes. Two-year follow-up data from a multicenter trial demonstrated that freedom from valve-related mortality, prosthetic valve endocarditis, and explantation was $99.4 \%, 98.6 \%$, and $99.4 \%$, respectively. ${ }^{8}$ In a series of 200 patients, Permanyer and associates ${ }^{9}$ reported satisfactory hemodynamic results for the Trifecta aortic valve prosthesis and no cases of PPM. As mentioned previously, Dell'Aquila and associates ${ }^{10}$ reported satisfactory clinical outcomes and hemodynamic performance in 50 patients who underwent AVR with the Trifecta prosthesis. Our study differs from these previous investigations by including comparison groups of 2 other types of pericardial aortic valves in a full range of valve sizes, and our data indicate a small but statistically significant hemodynamic advantage for the Trifecta valve in all labeled sizes.

Our results contrast with those from the recent study by Wendt and associates, ${ }^{11}$ who compared early hemodynamic performance of the Trifecta aortic prosthesis with that of the Perimount Magna and Magna Ease prostheses. First, these investigators examined Doppler echocardiographic data from predischarge studies and from examinations performed 6 months postoperatively. There were no important differences in mean gradients or EOAs between the 2 time points. Their data also demonstrated a slightly lower mean gradient with the Trifecta prosthesis than with the other pericardial valves (9.1 vs $11.2 \mathrm{~mm} \mathrm{Hg}$ for the Perimount Magna and $14.0 \mathrm{~mm} \mathrm{Hg}$ for the Magna Ease). However, there were significant differences in the preoperative characteristics of patients receiving the 3 valves, so further exploration of hemodynamic performance by multivariate covariance analysis was performed, which showed no influence of prosthesis type on mean pressure gradient or aortic valve area. In our study, although patients who received the Mitroflow valve had more combined procedures and risk factors, there were no important differences in baseline characteristics that might have influenced the gradients or valve areas. The study by Wendt and colleagues ${ }^{11}$ is unusual because the operative (30-day) mortality for the Trifecta valve was $8.3 \%$.

The Doppler echocardiographic assessment of EOA and EOAI is a useful measure of prosthetic valve function 
TABLE 4. Predischarge echocardiographic results for 1436 patients who underwent aortic valve replacement with 1 of 3 bovine bioprostheses*

\begin{tabular}{|c|c|c|c|c|}
\hline \multirow[b]{2}{*}{ Finding } & \multicolumn{3}{|c|}{ Bioprosthesis $(N=1436)$} & \multirow[b]{2}{*}{$P$ value } \\
\hline & Trifecta $(n=196)$ & Mitroflow $(n=1135)$ & Perimount Magna $(n=105)$ & \\
\hline Overall & $(\mathrm{n}=196)$ & $(\mathrm{n}=1135)$ & $(\mathrm{n}=105)$ & \\
\hline Preoperative LVOT index, $\mathrm{cm}$ & $1.18 \pm 0.1$ & $1.17 \pm 0.1$ & $1.17 \pm 0.2$ & .79 \\
\hline Postoperative $\mathrm{AV}$ mean gradient, $\mathrm{mm} \mathrm{Hg}$ & $11.4 \pm 4.2$ & $16.9 \pm 6.7$ & $14.1 \pm 5.4$ & $<.001$ \\
\hline Postoperative EOA, $\mathrm{cm}^{2}$ & $2.22 \pm 0.7$ & $1.85 \pm 0.5$ & $2.09 \pm 0.5$ & $<.001$ \\
\hline Postoperative EOAI, $\mathrm{cm}^{2} / \mathrm{m}^{2}$ & $1.14 \pm 0.3$ & $0.96 \pm 0.3$ & $1.07 \pm 0.3$ & $<.001$ \\
\hline Valve size $19 \mathrm{~mm}$ & $(\mathrm{n}=23)$ & $(\mathrm{n}=46)$ & $(\mathrm{n}=5)$ & \\
\hline Preoperative LVOT index, $\mathrm{cm}$ & $1.21 \pm 0.1$ & $1.22 \pm 0.1$ & $1.19 \pm 0.1$ & .77 \\
\hline Postoperative $\mathrm{AV}$ mean gradient, $\mathrm{mm} \mathrm{Hg}$ & $15.1 \pm 5.0$ & $21.3 \pm 9.1$ & $21.4 \pm 7.7$ & .011 \\
\hline Postoperative EOA, $\mathrm{cm}^{2}$ & $1.53 \pm 0.3$ & $1.23 \pm 0.3$ & $1.26 \pm 0.2$ & .001 \\
\hline Postoperative EOAI, $\mathrm{cm}^{2} / \mathrm{m}^{2}$ & $0.91 \pm 0.2$ & $0.78 \pm 0.3$ & $0.76 \pm 0.2$ & .04 \\
\hline Valve size $21 \mathrm{~mm}$ & $(\mathrm{n}=48)$ & $(\mathrm{n}=336)$ & $(\mathrm{n}=31)$ & \\
\hline Preoperative LVOT index, $\mathrm{cm}$ & $1.15 \pm 0.1$ & $1.19 \pm 0.1$ & $1.23 \pm 0.2$ & .08 \\
\hline Postoperative AV mean gradient, $\mathrm{mm} \mathrm{Hg}$ & $12.0 \pm 4.1$ & $18.4 \pm 6.5$ & $15.9 \pm 5.6$ & $<.001$ \\
\hline Postoperative EOA, $\mathrm{cm}^{2}$ & $1.84 \pm 0.4$ & $1.52 \pm 0.4$ & $1.73 \pm 0.2$ & $<.001$ \\
\hline Postoperative EOAI, $\mathrm{cm}^{2} / \mathrm{m}^{2}$ & $1.02 \pm 0.3$ & $0.87 \pm 0.2$ & $0.98 \pm 0.2$ & $<.001$ \\
\hline Valve size $23 \mathrm{~mm}$ & $(\mathrm{n}=62)$ & $(n=423)$ & $(\mathrm{n}=32)$ & \\
\hline Preoperative LVOT index, $\mathrm{cm}$ & $1.13 \pm 0.1$ & $1.15 \pm 0.1$ & $1.13 \pm 0.2$ & .25 \\
\hline Postoperative AV mean gradient, $\mathrm{mm} \mathrm{Hg}$ & $11.2 \pm 3.4$ & $17.2 \pm 6.2$ & $14.2 \pm 4.9$ & $<.001$ \\
\hline Postoperative EOA, $\mathrm{cm}^{2}$ & $2.23 \pm 0.5$ & $1.83 \pm 0.4$ & $2.01 \pm 0.3$ & $<.001$ \\
\hline Postoperative EOAI, $\mathrm{cm}^{2} / \mathrm{m}^{2}$ & $1.12 \pm 0.3$ & $0.94 \pm 0.2$ & $1.04 \pm 0.2$ & $<.001$ \\
\hline Valve size $25 \mathrm{~mm}$ & $(\mathrm{n}=42)$ & $(\mathrm{n}=262)$ & $(\mathrm{n}=29)$ & \\
\hline Preoperative LVOT index, $\mathrm{cm}$ & $1.21 \pm 0.1$ & $1.15 \pm 0.1$ & $1.12 \pm 0.1$ & .01 \\
\hline Postoperative AV mean gradient, $\mathrm{mm} \mathrm{Hg}$ & $10.0 \pm 3.7$ & $14.2 \pm 4.9$ & $11.8 \pm 3.6$ & $<.001$ \\
\hline Postoperative EOA, $\mathrm{cm}^{2}$ & $2.73 \pm 0.5$ & $2.28 \pm 0.5$ & $2.47 \pm 0.5$ & $<.001$ \\
\hline Postoperative EOAI, $\mathrm{cm}^{2} / \mathrm{m}^{2}$ & $1.33 \pm 0.3$ & $1.1 \pm 0.3$ & $1.17 \pm 0.2$ & $<.001$ \\
\hline Valve sizes $27 \mathrm{~mm}, 29 \mathrm{~mm}$, and $31 \mathrm{~mm}$ & $(\mathrm{n}=18)$ & $(\mathrm{n}=68)$ & $(\mathrm{n}=8)$ & \\
\hline Preoperative LVOT index, cm & $1.29 \pm 0.2$ & $1.22 \pm 0.2$ & $1.31 \pm 0.2$ & .18 \\
\hline Postoperative AV mean gradient, $\mathrm{mm} \mathrm{Hg}$ & $8.1 \pm 3.1$ & $13.9 \pm 4.8$ & $11.3 \pm 5.0$ & $<.001$ \\
\hline Postoperative EOA, $\mathrm{cm}^{2}$ & $3.2 \pm 0.8$ & $2.48 \pm 0.5$ & $2.8 \pm 0.5$ & .002 \\
\hline Postoperative EOAI, $\mathrm{cm}^{2} / \mathrm{m}^{2}$ & $1.51 \pm 0.3$ & $1.18 \pm 0.3$ & $1.33 \pm 0.3$ & $<.001$ \\
\hline
\end{tabular}

$A V$, Aortic valve; $E O A$, effective orifice area; EOAI, effective orifice area index; $L V O T$, left ventricular outflow tract. *Values are mean \pm standard deviation unless indicated otherwise.

because it is less dependent on transvalvular flow than assessment of peak or mean transvalvular gradients. The EOAI also is a useful measure of PPM, which has been shown to affect short- and long-term survival. ${ }^{17,21}$ Moderate PPM might be tolerated in elderly patients and those of smaller body size, ${ }^{22}$ but severe PPM has been shown to be particularly deleterious in young athletes and in high-risk patients with poor left ventricular function. ${ }^{21}$ Jamieson and colleagues ${ }^{23}$ reported reduced 10-year survival of patients with moderate and severe PPM after Mitroflow AVR (12.9\%) compared with patients with no PPM $(28.8 \%)$. In our study, risk of severe PPM with the Trifecta valve was only $1.3 \%$, which was lower than the risk with the other 2 pericardial bioprostheses.

In this report, transprosthetic gradients and valve areas may not correspond precisely to previously published data because our study used early postoperative Doppler echocardiogram measurements obtained at a mean of $4.7 \pm 2.6$ days after operation. Increased circulating catecholamines and dilutional anemia might have affected early postoperative mean gradient and peak velocity. ${ }^{20}$ However, these potentially confounding conditions would not be expected to affect EOA and EOAI. Mid-term follow-up will be necessary before definitive conclusions can be drawn regarding postdischarge hemodynamic differences among these 3 devices.

\section{Study Limitations}

We studied early hemodynamics at rest for all 3 valves at hospital discharge. It is possible that minor differences might occur after exercise assessment; however, in clinical practice, the measurement of resting hemodynamics with additional maneuvers is a commonly accepted standard for evaluation of prosthetic valve function early after surgery. ${ }^{16}$ The external diameter of the sewing rings may differ from the labeled valve size, and without direct measurement of LVOT dimension using a universal sizer at surgery, one might argue that valves with differing internal dimensions were compared using labeled valve size alone. ${ }^{3}$ To address this potential bias, we compared the preoperative LVOT 


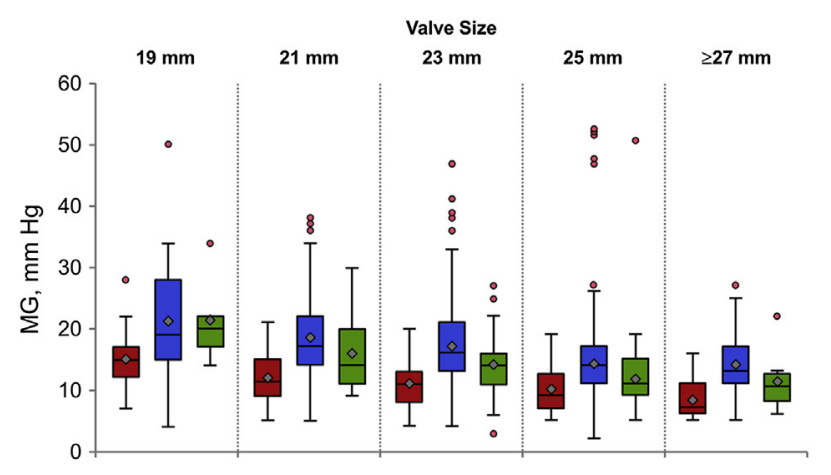

Longitudinal clinical and echocardiographic assessments will be necessary to determine whether these small hemodynamic differences persist and influence mid- to lateterm clinical outcomes.

\section{References}

1. Bonow RO, Carabello BA, Chatterjee K, de Leon AC Jr, Faxon DP, Freed MD, et al; 2006 Writing Committee Members. American College of Cardiology/ American Heart Association Task Force. 2008 Focused update incorporated into the ACC/AHA 2006 guidelines for the management of patients with valvular heart disease: a report of the American College of Cardiology/American Hear Association Task Force on Practice Guidelines (Writing Committee to Revise the 1998 Guidelines for the Management of Patients With Valvular Heart Disease): endorsed by the Society of Cardiovascular Anesthesiologists, Society for Cardiovascular Angiography and Interventions, and Society of Thoracic Surgeons. Circulation. 2008;118:e523-661.

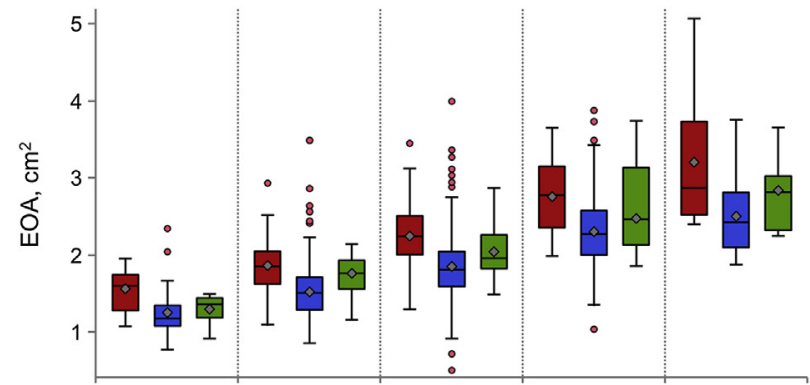

2. Chambers JB, Rajani R, Parkin D, Rimington HM, Blauth CI, Venn GE, et al. Bovine pericardial versus porcine stented replacement aortic valves: early results of a randomized comparison of the Perimount and the Mosaic valves. J Thorac Cardiovasc Surg. 2008;136:1142-8.

3. Dalmau MJ, Gonzalez-Santos JM, Blazquez JA, Sastre JA, Lopez-Rodriguez J, Bueno M, et al. Hemodynamic performance of the Medtronic Mosaic and Perimount Magna aortic bioprostheses: five-year results of a prospectively randomized study. Eur J Cardiothorac Surg. 2011;39:844-52.

4. Borger MA, Nette AF, Maganti M, Feindel CM. Carpentier-Edwards Perimount Magna valve versus Medtronic Hancock II: a matched hemodynamic comparison. Ann Thorac Surg. 2007;83:2054-8.

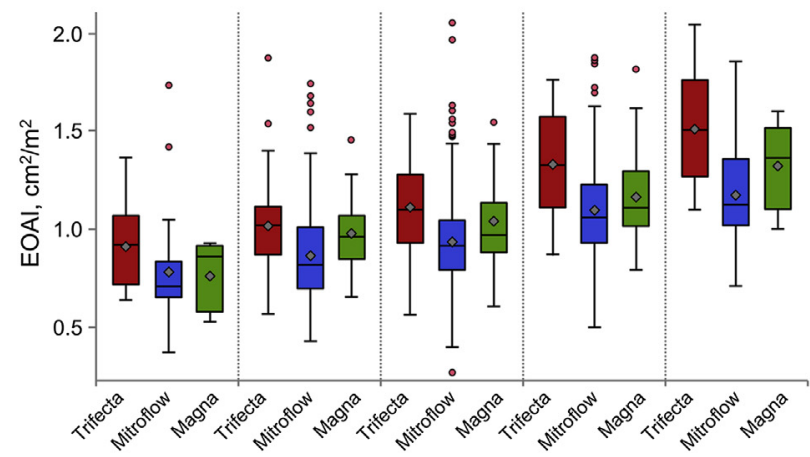

5. Asch FM, Heimansohn D, Doyle D, Dembitsky W, Ferdinand FD, Swanson J, et al. Mitroflow aortic bioprosthesis 5-year follow-up: North American prospective multicenter study. Ann Thorac Surg. 2012;94:1198-203.

6. Yankah CA, Pasic M, Musci M, Stein J, Detschades C, Siniawski H, et al. Aortic valve replacement with the Mitroflow pericardial bioprosthesis: durability results up to 21 years. J Thorac Cardiovasc Surg. 2008;136:688-96.

7. ISTHMUS Investigators. The Italian study on the Mitroflow postoperative results (ISTHMUS): a 20-year, multicentre evaluation of Mitroflow pericardial bioprosthesis. Eur J Cardiothorac Surg. 2011;39:18-26.

8. Bavaria JE, Desai ND, Cheung A, Petracek MR, Groh MA, Borger MA, et al. The St Jude Medical Trifecta aortic pericardial valve: results from a global, multicenter, prospective clinical study. J Thorac Cardiovasc Surg. 2014;147:590-7.

9. Permanyer E, Estigarribia AJ, Ysasi A, Herrero E, Semper O, Llorens R. St. Jude Medical Trifecta ${ }^{\mathrm{TM}}$ aortic valve perioperative performance in 200 patients Interact Cardiovasc Thorac Surg. 2013;17:669-72.

FIGURE 1. Discharge echocardiographic findings for 1436 patients stratified by valve size for the Trifecta (St Jude Medical, St Paul, Minn), Mitroflow (Sorin Group, Milan, Italy), and Perimount Magna (Edwards Lifesciences Corp, Irvine, Calif) bovine aortic valve bioprostheses. Top of box-and-whiskers plots shows that the average mean gradient was significantly lower across valve sizes ( $19 \mathrm{~mm}, 21 \mathrm{~mm}, 23 \mathrm{~mm}, 25 \mathrm{~mm}$, and $\geq 27$ $\mathrm{mm}$ ) for the Trifecta valve. Middle shows that the mean EOA was significantly greater across valve sizes for the Trifecta valve. Bottom shows that the mean EOAI was significantly higher across valve sizes for the Trifecta valve. Mean and median are represented by the diamond and horizontal line, respectively, inside each colored box. Area between the top and bottom borders (ie, whiskers) represents the middle $50 \%$ of the data. $E O A$, Effective orifice area; EOAI, effective orifice area index; $M G$, mean gradient.

index of the patients for each valve size and found no important differences.

\section{CONCLUSIONS}

The early hemodynamic performance of the new Trifecta bioprosthesis compared with that of 2 better known devices was favorable at the time of discharge from the hospital.

10. Dell'Aquila AM, Schlarb D, Schneider SR, Sindermann JR, Hoffmeier A Kaleschke G, et al. Clinical and echocardiographic outcomes after implantation of the Trifecta aortic bioprosthesis: an initial single-centre experience. Interact Cardiovasc Thorac Surg. 2013;16:112-5.

11. Wendt D, Thielmann M, Plicht B, Aßmann J, Price V, Neuhauser M, et al. The new St Jude Trifecta versus Carpentier-Edwards Perimount Magna and Magna Ease aortic bioprosthesis: is there a hemodynamic superiority? J Thorac Cardiovasc Surg. 2013 [Epub ahead of print].

12. Minami K, Zittermann A, Schulte-Eistrup S, Koertke H, Korfer R. Mitroflow synergy prostheses for aortic valve replacement: 19 years experience with 1,516 patients. Ann Thorac Surg. 2005;80:1699-705.

13. Conte J, Weissman N, Dearani JA, Bavaria J, Heimansohn D, Dembitsky W, et al A North American, prospective, multicenter assessment of the Mitroflow aortic pericardial prosthesis. Ann Thorac Surg. 2010;90:144-52.

14. Daneshvar SA, Rahimtoola SH. Valve prosthesis-patient mismatch (VP-PM): a long-term perspective. J Am Coll Cardiol. 2012;60:1123-35.

15. Botzenhardt F, Eichinger WB, Bleiziffer S, Guenzinger R, Wagner IM Bauernschmitt R, et al. Hemodynamic comparison of bioprostheses for complete supra-annular position in patients with small aortic annulus. J Am Coll Cardiol. 2005;45:2054-60.

16. McDonald ML, Daly RC, Schaff HV, Mullany CJ, Miller FA, Morris JJ, et al. Hemodynamic performance of small aortic valve bioprostheses: is there a difference? Ann Thorac Surg. 1997;63:362-6.

17. Walther T, Rastan A, Falk V, Lehmann S, Garbade J, Funkat AK, et al. Patient prosthesis mismatch affects short- and long-term outcomes after aortic valve replacement. Eur J Cardiothorac Surg. 2006;30:15-9.

18. Smedira NG, Blackstone EH, Roselli EE, Laffey CC, Cosgrove DM. Are allografts the biologic valve of choice for aortic valve replacement in nonelderly 
patients? comparison of explantation for structural valve deterioration of allograft and pericardial prostheses. J Thorac Cardiovasc Surg. 2006;131:558-64.e4.

19. Minardi G, Pulignano G, Del Sindaco D, Sordi M, Pavaci H, Pergolini A, et al. Early Doppler-echocardiography evaluation of Carpentier-Edwards Standard and Carpentier-Edwards Magna aortic prosthetic valve: comparison of hemodynamic performance. Cardiovasc Ultrasound. 2011;9:37.

20. Suri RM, Michelena HI, Burkhart HM, Greason KL, Daly RC, Dearani JA, et al. A prospective, randomized comparison of 3 contemporary bioprosthetic aortic valves: should hemodynamic performance influence device selection? J Thorac Cardiovasc Surg. 2012;144:1387-95, 1398.
21. Bleiziffer S, Eichinger WB, Hettich I, Guenzinger R, Ruzicka D, Bauernschmitt R, et al. Prediction of valve prosthesis-patient mismatch prior to aortic valve replacement: which is the best method? Heart. 2007;93: 615-20.

22. Moon MR, Pasque MK, Munfakh NA, Melby SJ, Lawton JS, Moazami N, et al. Prosthesis-patient mismatch after aortic valve replacement: impact of age and body size on late survival. Ann Thorac Surg. 2006;81:481-8.

23. Jamieson WR, Koerfer R, Yankah CA, Zittermann A, Hayden RI, Ling H, et al. Mitroflow aortic pericardial bioprosthesis: clinical performance. Eur J Cardiothorac Surg. 2009;36:818-24. 